\title{
Diversity and inclusion management: an analysis of practice developments in Italy ${ }^{1}$
}

\section{Silvia Ravazzani - Alessandra Mazzei - Chiara Fisichella} Alfonsa Butera

\begin{abstract}
Frame: Diversity and inclusion management is a fast-growing concept and practice in Italy. An analysis of practice developments requires focusing on the Italian contextual change (i.e., macro-national trends) while also considering organizationalspecific conditions.

Purpose: To explore how diversity and inclusion management is currently understood and acted upon in the Italian workplace, taking into consideration practice developments.

Methodology: Two case studies of large, multinational companies operating in Italy based on interviews and documentary analysis.

Results: The comprehension and practices related to diversity and inclusion in Italy are evolving towards a leveraging variety perspective to increase innovation and competition outcomes. Furthermore, a nuanced and holistic approach emerges, embracing the variety of the whole person for motivation and wellbeing purposes too. Finally, to manage the risk of losing a shared purpose of the organizing process coming from heterogeneity, internal variety is valued by balancing the need for coherence and unity of action with a culture of diversity and an inclusive language, integrating diversity and inclusion management into core processes and implementing it as part of the company mission.

Research limitations: More cases should be analysed to delve further into current approaches and explanatory contingency factors.

Practical Implications: Organizations should base their approach to diversity and inclusion on nation- and organization-focused sensitivity, considering among others legal and societal expectations and restraints as well as organizational priorities and culture. Furthermore, organizations should adopt ad hoc practices to balance the tensions between the quest for heterogeneity and the quest for a shared purpose.

Originality: This article contributes to diversity research outside of the US, which is much needed. In particular, it scrutinizes practice developments in Italy by building on previous studies carried out in this country according to a longitudinal perspective. Moreover, it offers a detailed qualitative examination accounting for organizational contextual elements too.
\end{abstract}

Key words: diversity management; inclusion; equality; valuing people; macro-national system; organizational context

1 This work was supported by the Working Group Employee Communication 2020-2022 @Centre for Employee Relations and Communication (CERC), IULM University. 


\section{sinergie}

Vol. 39, Issue 3, 202

\section{Introduction}

Equality, diversity and inclusion are intertwined terms (Frémeaux, 2020) that have been at the centre of societal, academic and organizational debate for a long time. North America was the first to introduce legal protections and business policies to facilitate job openings and improve working conditions for minorities (Jonsen et al., 2011). The same term "diversity management" was introduced for the first time in the US in 1987, when the report Workforce 2000 by Johnston and Packer popularized the increasing heterogeneity of the American workforce and the need for society and organizations alike to face this reality (Kandola and Fullerton, 2004). Since then, national and supra-national laws and recommendations, academic and professional publications and conferences as well as organizational practices have been developed all over the world, under the pressure exerted by globalization, immigration, labour mobility and greater sensitivity in society towards minorities' rights and organizations' socially responsible conduct (e.g., De Anca and Vásquez, 2007; Shen et al., 2009). From an academic viewpoint, research in this area crystallized as a management subfield in the late 1980s (Konrad, 2003) and from that moment on has been developing fast offering a significant variety of conceptualizations, models, empirical results, and management principles. Most of these studies have been developed in the US, which points to the need for non US centric diversity research (Klarsfeld, 2009; Jonsen et al., 2011).

In Italy, diversity management is a fast-growing concept and practice that started to disseminate in the 2000s (Mazzei and Ravazzani, 2008, 2012; Murgia and Poggio, 2014; Ravazzani, 2016). It has been gaining ground over recent years driven by the increased labour-force participation of women and immigrants, the extention of the working age, the guidelines offered by the EU, and the exemplary initiatives imported by multinational companies. Recent reports depict the main current challenges for Italian organizations. For example, the Global Gender Gap Report 2020 of the World Economic Forum (2019) highlights that the average index for wage equity for equal work between males and females is $61.3 \%$ worldwide, whereas the index drops to $52.9 \%$ in Italy. The European LGBTI Survey conducted by the European Union Agency for Fundamental Rights (2020) outlines that 53\% of LGBTI rarely or never declare their sexual orientation; in Italy, this percentage rises to $62 \%$. Moreover, this survey shows that $21 \%$ of LGBTI in Europe perceive discrimination at work, with Italian respondents being aligned (22\%). Lately, the Covid-19 pandemic has created new challenges for diverse employees, above all for women and working parents (Ellingrud et al., 2020).

Previous research carried out in other European countries (e.g., Svetelik, 2006) stressed that differences in the social, economic, and historical contexts of countries shape employment policies and practice at both organizational and institutional levels, as well as individual experiences in the labour market. Such country-rooted social, economic, and historical contexts therefore frame and influence diversity and inclusion strategy and practices and must be accounted for through contextualized explanations 
(Jonsen et al., 2011). While previous research in Italy (e.g., Mazzei and Ravazzani, 2008, 2012; Murgia and Poggio, 2014; Ravazzani, 2016) started to explore diversity management characteristics and practices, there is a need for a new investigation that considers the changed social, economic, and historical conditions in which Italian organizations currently operate.

While framed within the macro-national context, a company's approach to diversity and inclusion is likely to be shaped also by organizationspecific variables (Olsen and Martins, 2012; Shore et al., 2009). Among others, the company's diversity climate or culture embedded into the larger core corporate culture and values, its demographic makeup, level of internationalization, industry, business strategy and market position.

This article takes into consideration the need for contextualized explanations of diversity and inclusion practices, responding to the call for country-sensitive research and especially developed outside of the US (Klarsfeld, 2009; Jonsen et al., 2011) as well as for research considering organization-specific elements (Olsen and Martins, 2012; Shore et al., 2009). Building on previous theoretical and empirical contributions focused on diversity and inclusion in Italy (specifically Mazzei and Ravazzani, 2012; Ravazzani, 2016) in a longitudinal perspective, this qualitative study aims to investigate how diversity and inclusion management is currently understood and acted upon in Italy, taking into consideration practice developments.

This article first introduces organizational approaches to managing diversity and arrives at illustrating a comprehensive model based on practice-driven indicators that was previously tested in the Italian context. Second, it presents an empirical study based on two case studies of Italian organizations. Findings articulate the diversity and inclusion policy features linked to the country characteristics as well as to the specific organizational contexts under study. After discussing key insights deriving from the empirical study, the article concludes with theoretical and managerial implications and avenues for future research.

\section{Organizational approaches to managing diversity}

The rich history of research on and practice of diversity and inclusion starts in the 1960s in North America, where equal employment opportunity laws were first introduced (Jonsen et al., 2011). Over the years, organizations started to adopt a more proactive and deliberate approach pushed by the emerging conviction that diversity creates competitive advantages (Cox and Blake, 1991). This entailed a shift from a focus on few sociodemographic dimensions to an enlarged array of diversity dimensions, with the development of strategies aimed at embracing the variety of the whole person (Mazzei and Ravazzani, 2012; Milliken and Martins, 1996; Ravazzani, 2016).

In the academic field, international scholars put their effort in developing typologies classifying diversity-related managerial approaches based on the level of organizational heterogeneity and/or cultural perspective adopted towards diversity (Cox, 1991; De Anca and Vásquez, 2007; Liff, 1997; Thomas and Ely, 1996). Such typologies contributed to inspire a large 
sinergie Vol. 39, Issue 3, 202

debate both in the academic and professional communities. Nonetheless, they present some major limitations: they do not take into consideration contextual factors, especially the country where an organization operates which influences diversity issues, organizational priorities, legal and societal restraints (Klarsfeld, 2009; Shen et al., 2009); they do not put in sufficient light the fact that organizations do not necessarily follow an evolutionary path in approaching diversity management (Sü $\beta$ and Kleiner, 2008; Klarsfeld, 2009); most of them neither detail practice-driven indicators to understand how organizations behave beyond espoused statements (Olsen and Martins, 2012) nor link overarching approaches with organizational contextual factors (Jonsen et al., 2011).

Keeping in mind such limitations, Mazzei and Ravazzani $(2008,2012)$ and Ravazzani (2016) developed a model that builds on and extends extant typologies from international literature. The model details three possible approaches to diversity management: "Assimilating Minorities", focused on guaranteeing equal opportunities for traditionally under-represented groups and legally protected attributes, with few practices and resources in place; "Integrating Diversity", geared towards addressing social expectations with voluntarily actions considering a greater array of socio-demographic features and of managerial practices; and "Leveraging Variety", a more structured approach attentive towards competitive advantages accessible through the variety of competencies and knowledge-related differences of employees. The model outlines a set of indicators that help detect which approach organizations embrace based on what they actually do, i.e., aim, dimensions, practices, management structure, benefits, negative effects. Additionally, it assumes that elements typical of an approach can co-exist in a particular organizational context and be re-elaborated according to the specific national context of reference.

Figure 1 visualizes in detail this research model, which offers a tool for understanding how companies might work with diversity in practice under a certain dominant perspective.

To test this model in Italy, Ravazzani (2016) conducted an empirical study based on a survey and two focus groups with managers and experts. Results related to the practice-driven indicators revealed the prevalence of an "Integrating Diversity" approach: companies mainly focused on addressing internal and external social expectations, placed centrality on gender and parenthood discourse, and valued practices aimed at internal wellbeing (e.g., work-life balance policies) and external reputation (e.g., partnerships with external institutions), which clearly reflects the priorities in the social agenda and legislative make-up of Italy. She also tested the role of organizational contextual factors that may influence the adoption of a certain organizational approach (Olsen and Martins, 2012; Shore et al., 2009): diversity culture; level of internationalization; and business strategy. Interestingly, results indicated that companies most focused on meeting social expectations are of Italian origin and do not have a long history of diversity commitment, apparently influenced by isomorphic pressures and the need to secure legitimacy in their environment. Also, equal opportunities appeared as an ever-present milestone in Italian organizations, regardless of the length of their commitment and corporate 
culture, while only internationalization explained the probability that Italian organizations would pursue competition through diversity. On the whole, previous empirical findings highlight that Italian organizations have not followed a temporal or stepwise progression in their diversity approach and that the business case for diversity in this country reflects both the macro socio-cultural system and organization-related contextual factors.
Silvia Ravazzani Alessandra Mazzei Chiara Fisichell Alfonsa Butera

Diversity and inclusion management: an analysis management. an analysis of practice development in Italy

Fig. 1: A practice-driven framework: from Assimilating minorities, to Integrating diversity, to Leveraging variety

\begin{tabular}{|c|c|c|c|}
\hline Indicators Approach & $\begin{array}{l}\text { Assimilating } \\
\text { Minorities }\end{array}$ & $\begin{array}{l}\text { Integrating } \\
\text { Diversity }\end{array}$ & $\begin{array}{l}\text { Leveraging } \\
\text { Variety }\end{array}$ \\
\hline Aim & Equal opportunities & Social expectations & Competition \\
\hline Dimensions & $\begin{array}{ll}\text { G e n d e r , } \\
\text { parenthood, } \\
\text { disability }\end{array}$ & $\begin{array}{l}\text { Race, nationality, } \\
\text { language, religion, sexual } \\
\text { orientation, age }\end{array}$ & $\begin{array}{l}\text { Competencies, knowledge, } \\
\text { networks }\end{array}$ \\
\hline Practices & Quota systems & $\begin{array}{l}\text { Flexible working, work- } \\
\text { life balance, expansion } \\
\text { of the recruitment pool, } \\
\text { training, partnerships } \\
\text { with dedicated } \\
\text { institutions and networks, } \\
\text { internal and external } \\
\text { communication }\end{array}$ & $\begin{array}{lr}\text { Heterogeneous } & \text { teams, } \\
\text { employee } & \text { networks, } \\
\text { diverse } & \text { suppliers, } \\
\text { employment } & \text { in } \\
\text { innovation-related } & \text { areas, } \\
\text { evaluation of policy } \\
\text { objectives }\end{array}$ \\
\hline $\begin{array}{l}\text { Management } \\
\text { structure }\end{array}$ & Barely existent & $\begin{array}{l}\text { Dedicated role and } \\
\text { planning }\end{array}$ & $\begin{array}{l}\text { Dedicated structure, } \\
\text { planning and budget }\end{array}$ \\
\hline Benefits & $\begin{array}{l}\text { Equity of treatment, } \\
\text { reduced lawsuits }\end{array}$ & $\begin{array}{l}\text { Employee motivation, } \\
\text { corporate image }\end{array}$ & Innovation, new markets \\
\hline Negative effects & $\begin{array}{l}\text { Lowering of hiring } \\
\text { and promotion } \\
\text { standards, negative } \\
\text { self-perceptions of } \\
\text { competence }\end{array}$ & $\begin{array}{l}\text { Increased conflicts, } \\
\text { reverse discrimination }\end{array}$ & Pigeonholing \\
\hline
\end{tabular}

Source: Ravazzani, 2016.

\section{Methodology}

Following this line of context-sensitive diversity research and adopting a longitudinal perspective, this study builds on the practice-driven framework and related empirical findings (Mazzei and Ravazzani, 2012; Ravazzani, 2016) and adopts a case study methodology for gaining rich insights into how diversity and inclusion management is currently understood and acted upon in Italy, taking into consideration practice developments.

Case study research allows researchers to produce concrete knowledge embedded in real-life situations and with multiple wealth of details (Flyvbjerg, 2006). Following an information-oriented selection to maximize the usefulness of information from small samples and single cases, this study considered for in-depth analysis two organizations of large size, with multinational presence, and with a formal diversity policy as publicly stated on their corporate website. Company A has foreign origins and operates in the telecommunications sector, employing about 6,000 people in Italy. Company B is Italian and is an energy infrastructure operator, employing about 3,000 people in Italy. 
sinergie Vol. 39, Issue 3, 2021

The researchers collected multiple forms of evidence for quality case study research (Yin, 2003) between November 2020 and February 2021 through desk data analysis focused on corporate documentary sources, e.g., corporate presentations of diversity policies and practices and dedicated pages from the corporate website; and field data analysis focused on qualitative interviews with managers responsible for diversity and inclusion in their organization. The two managers interviewed from Company and A and the one from Company B work in the areas of human resource management and of employee communication.

Interviews were carried out to gather perspectives and concrete experiences of "knowledgeable agents" (Gioia et al., 2013) telling their own stories in their own words (Daymon and Holloway, 2011). Following a semi-structured approach, interviews addressed managers' experiences, behaviour, and opinions (Patton, 2002) in relation to their understanding of diversity, the specific make-up of their workplace, and practice-driven indicators. Interviews were conducted electronically via Microsoft Teams due to the current pandemic context, each lasting on average 60 minutes. They were video-recorded and transcribed for analytical purposes to identify central concepts and then themes and patterns within and across interviews (Gioia et al., 2013), which were further integrated with insights from the thematic analysis performed on company documents.

Below, key results from the analysis are firstly presented case by case, and then visually compared through Figure 2 according to the practicedriven framework. The comparison is further expounded in the discussion section.

\section{Findings}

In Company $\mathrm{A}$, the diversity management aim changed over the years. The path started in 2014 with some internal initiatives, but a more structured commitment started in 2016 when the company joined the United Nations Global Solidarity Movement for Gender Equality with the "HeforShe" programme. The global CEO was an ambassador for the programme. In the same year, the company organized an internal roadshow in Italy involving 600 employees to define the company inclusion agenda, the so-called "Manifesto". With a bottom-up approach, employees worked together to outline more than 100 proposals in four inclusion areas: gender, to increase equality; sexual orientation, to foster respect for people of any orientation; generation, to value the contribution of people of all ages; background, to embrace employees of different cultures or from different company branches. Employees, moreover, co-created the company inclusive mission: "a declaration that is still hanging on all company billboards", the internal communication manager reveals. The "Manifesto" was a fundamental step in the diversity management approach of Company A, also leading to the concrete implementation of a series of initiatives proposed by employees themselves. On that occasion, the figure of the Inclusion Leader was also established: about twenty managers were assigned to all of the four areas. 
In 2020, the aim of Company A shifted from managing diversity to managing inclusion. In the words of the HR manager, "if diversity was seen primarily as an ethical issue, inclusion is now framed as a business value in terms of corporate reputation and employee engagement and attractiveness". "Inclusion for all" is now one of the three purpose pillars of the company strategic framework. Again, the HR manager underlines: "This puts diversity and inclusion at the core of the corporate mission. The goal is also to create a workforce that mirrors and understands customers' differences".

Gender and parenthood emerge as the main diversity dimensions currently addressed. In fact, most common practices are mostly related to promoting equality through: maternity and parental leave policies that go beyond those granted by law; parental smart working policies; work shifts policies that accommodate childcare needs. In addition, over the years Company A developed two hiring programmes for women: "Plus 1 Woman", an internal programme consisting in hiring one more woman in a managerial position for each department; and "ReConnect", an external programme focused on reintegrating women into the labour market after having resigned or lost their jobs. Considering the gender dimension, the company is also a founding member of "Valore D", a project supporting companies in developing growth paths for female talents and supporting their path to top management positions. In Company A, approximately $30 \%$ of people having managerial responsibilities are women. Company A is also committed against domestic women violence with internal policies and external actions, e.g., a mobile app that helps women to react to domestic violence.

In the last few years, Company A worked actively also on another diversity dimension: sexual orientation. The HR manager highlights in this context that "one of the first steps was working on inclusive language": in 2017 the company promoted a training programme for all managers called "Be Inclusive" focused on the LGBT theme. Nowadays, there is an internal community on sexual orientation with a chairperson and a top manager as a sponsor.

For the future, Company A intends to work more on the age dimension, after realizing that only $18 \%$ of employees are over the age of 50 . Another future topic is neurodiversity to develop talent.

While in the past local offices could independently decide on the focus and intervention in the area of diversity and inclusion, nowadays the global Group is "much more directive and enlightening, because there are issues that we don't see, or we do see too late" as the HR manager highlights. For instance, the global headquarters suggested to focus on ethnicity, following the Black Lives Matter movement, even though this was not initially perceived as a hot topic by the Italian local office.

Practices are communicated internally through the newsletter and the Intranet. Also, the HR manager reveals the company's efforts "to make communication more interactive involving employees as ambassadors". Externally, Company A communicates only the most important initiatives. To improve the storytelling of their commitment, in 2020 they carried out a communication campaign to address the issue of diversity inequality in the technology industry. 
sinergie Vol. 39, Issue 3, 2021

Considering the managerial structure, Company A does not have a dedicated organizational unit but a person in charge of managing diversity and inclusion initiatives. A specific budget is allocated to this area. Considering the global company, each country has a referent who communicates with the headquarters. Moreover, the Inclusion Leaders still exist even if less involved. For the future, the company intends to locate a sponsor for each stream of work, responsible for creating communities and coordinating with the D\&I Lead.

Regarding the benefits, Company A measured greater voice behaviours among employees about diversity. The HR manager cites as an example that "after the roadshow the company witnessed a growing number of employees coming out, and also in the last internal climate survey more than $80 \%$ of employees declared their sexual orientation". Moreover, in 2021 Company A was recognized as one of the twenty most inclusive brands in Italy by the Diversity Brand Index 2021, a research project promoted by Diversity and Focus MGMT and aimed at measuring the ability of companies to effectively develop a company culture oriented to diversity and inclusion. Company A was selected specifically for its commitment to fighting all forms of violence against women.

On the other side, Company A experienced negative effects in forcing a KPI related to achieving a greater gender mix in the "Plus 1 Woman" initiatives. As explained by the HR manager, "establishing a percentage of women to be placed in top positions created an opposite effect in the male workforce who did not recognize the value of this initiative". Moreover, women seem to remain a step back to men: "typically, a woman does not ask more in terms of salary and career in comparison to a man with the same experience and competence in the company". This is also an effect of the KPI in that "women wait and do not claim". Company A is now working on mending these issues. According to the manager, another negative effect of forcing a greater gender mix is that "managers aiming for one man and one woman often fail to search for the best talents regardless of their gender".

In Company $\mathrm{B}$, the diversity management aims are making the company more competitive and innovative through different skills and competences, fostering integration between different business areas, and increasing effectiveness in innovation processes and interdisciplinary projects. Moreover, in the words of the interviewed manager, Company B aims to create "a corporate culture that is inclusive and respectful of diversity, thanks to a safe and welcoming work environment". Safety is one of the key company values and "protecting diversity is a way to make employees feel safe when they express their personality and needs". The diversity commitment started in 2017 thanks to the CEO's endorsement.

Considering the diversity dimensions, gender was the first to be addressed with the goal to attract and promote women in the professional fields linked to the company. Like Company A, Company B is a founding member of "Valore D", and participates in the Inclusion Impact Index developed by this Italian association which provides a sector benchmark related to governance and ability to attract and retain female talents. The company's index in 2019 was 54.1/100, with a satisfactory recognition in terms of talent development but a lower performance in terms of 
attractiveness towards the female labour market. In terms of numbers, in Company B women account for nearly $15 \%$ of the employees, 1.5 points more than in 2017; four of them work in the leadership teams. Recently, Company B has begun to work also on: generational diversity, where $36 \%$ of the employee population is represented by Millennials; sexual orientation, becoming a member of Parks, a non-profit organization focused on people belonging to the LGBT category; disability; and cultural diversity.

Regarding the choice of the diversity dimensions to work on, Company $B$ regularly performs an international benchmark to assess whether there are dimensions that are not current issues in the Italian context but are much more important in other countries, for instance LGBT in the US.

The key practices are focused on promoting a culture of respect towards diversity in a broader sense. Company B has begun to work on all the diversity dimensions with the aim of valuing "personality diversity". Such practices cover four main areas: employer branding and talent acquisition, to ensure equal opportunities to external candidates; training, to increase internal awareness of diversity issues; development, to consolidate a diversity culture within the company's value system; communication, to spread an inclusive language throughout the organization. Examples of practices include a diversity policy considered by the manager as essential "to guarantee fairness in all phases of employment, training, and work-life balance initiatives"; a training video on unconscious biases in the selection process; training talks about diversity issues; a diversity performance management system; a Manifesto promoting the use of an inclusive language. Regarding inclusive language, Company B has organized two training sessions for People managers focused on generational and sexual orientation diversity.

Considering the gender dimension, the first to be addressed by this company, some practices aim to attract and promote women in the scientific fields. They cover three stakeholder groups: community, e.g., through scholarships devoted to high school female students; employees, e.g., through programmes that develop managerial skills of working parents; partners, e.g., through the collaboration with actors and institutions expert in the area of gender diversity.

Practices are communicated internally through the Intranet and emails, regarded by the manager as crucial "to push initiatives to all the company population". Externally, Company B relies on social media, especially LinkedIn and Instagram, and press releases to give visibility in the media to the most important initiatives.

Considering the managerial structure, in 2020 Company B created a new team called "Human Capital Development, Diversity \& Inclusion". This unit supports the diversity and inclusion goals defined by the top management, in alignment with the corporate strategy. These goals are integrated with environmental, social and governance (ESG) factors in both long and short-term incentive policies. While cooperating with the function responsible for ESG policies, the unit also coordinates a crossfunctional team called "Inclusion team". The team involves 35 employees responsible for proposing, directing and monitoring all initiatives related to the development of an inclusive organizational culture. To find the
Silvia Ravazzani

Alessandra Mazze

Chiara Fisichella

Alfonsa Butera

Diversity and inclusion

management: an analysis of practice developments
in Italy 
sinergie Vol. 39, Issue 3, 202

members of the Inclusion team, Company B launched a call to action to which 150 employees signed up. The manager explains that the company selected the Inclusion team members "covering all the company functions and considering diversity in terms of age, gender, hierarchical level, country of origin, culture, disability, sexual orientation and personal style". The team has a dedicated budget and presents its plan and results twice a year to a steering diversity and inclusion committee.

Regarding the benefits, since 2020 Company B has measured how much employees felt included getting excellent results according to the company's expectations. Considering the gender and generational diversity, the company ended up hiring more women and young people. Moreover, in 2020 Company B had their first female factory worker. Perceived benefits also include the possibility of being part of a network of companies dealing with diversity issues. All in all, the manager states that for the time being Company B "does not experience significant negative effects related to their diversity initiatives and policies". Figure 2 offers a comparative view of the two analysed cases based on the practice-driven framework.

Fig. 2: A comparison of the two diversity and inclusion programs based on the practice-driven framework

\begin{tabular}{|c|c|c|}
\hline Indicators & Company A & Company B \\
\hline Aim & $\begin{array}{l}\text { Social expectations, yet inclusion is } \\
\text { increasingly regarded as a business } \\
\text { value and part of the corporate } \\
\text { mission }\end{array}$ & $\begin{array}{l}\text { Competitiveness through different skills } \\
\text { and competences coupled with attention } \\
\text { to creating a safe and welcoming work } \\
\text { environment, where inclusion ensures } \\
\text { employees' feelings of safety and well- } \\
\text { being }\end{array}$ \\
\hline Dimensions & $\begin{array}{l}\text { Gender, parenthood, sexual } \\
\text { orientation, age/generation }\end{array}$ & $\begin{array}{l}\text { Gender, parenthood, sexual orientation, } \\
\text { age/generation, disability, culture from a } \\
\text { perspective of "personality diversity" }\end{array}$ \\
\hline Practices & $\begin{array}{l}\text { Gender -based hiring quotas, work- } \\
\text { life balance policies, training, internal } \\
\text { communication (e.g., billboards with } \\
\text { diversity mission and manifesto } \\
\text { of inclusive language), external } \\
\text { communication and actions (e.g., } \\
\text { partnerships with institutions, public } \\
\text { awards) }\end{array}$ & $\begin{array}{l}\text { Employer branding and extension } \\
\text { of the recruitment pool, work-life } \\
\text { balance initiatives, training, internal } \\
\text { communication (e.g., manifesto } \\
\text { of inclusive language), external } \\
\text { communication and actions (e.g., } \\
\text { partnerships with institutions) }\end{array}$ \\
\hline $\begin{array}{l}\text { Management } \\
\text { structure }\end{array}$ & $\begin{array}{l}\text { Coordinating role, Inclusion } \\
\text { Leaders, and dedicated budget; top } \\
\text { management endorsement }\end{array}$ & $\begin{array}{l}\text { Dedicated unit also coordinating } \\
\text { a cross-functional Inclusion team, } \\
\text { budget, planning accompanied with } \\
\text { diversity performance evaluation and in } \\
\text { alignment with corporate strategy; top } \\
\text { management endorsement }\end{array}$ \\
\hline Benefits & $\begin{array}{l}\text { Improved corporate reputation, } \\
\text { employee } \\
\text { attractiveness for less represented } \\
\text { categories, voice behaviours, } \\
\text { customers' understanding }\end{array}$ & $\begin{array}{l}\text { Improved employee engagement and } \\
\text { attractiveness for less represented } \\
\text { categories, networking with other } \\
\text { companies, innovation capabilities }\end{array}$ \\
\hline $\begin{array}{l}\text { Negative } \\
\text { effects }\end{array}$ & $\begin{array}{l}\text { Reverse discrimination felt by men; } \\
\text { quotas do not guarantee that the best } \\
\text { talents are hired }\end{array}$ & Perceived as not surfaced yet \\
\hline
\end{tabular}

Source: own elaboration 


\section{Discussion and conclusions}

Silvia Ravazzani

Alessandra Mazze

Chiara Fisichella

Alfonsa Butera

Diversity and inclusion

management: an analysis

This study investigated how diversity and inclusion management is evolving in the Italian workplace looking at practice developments. From the analysis of the two case studies some common elements stand out.

First, taking stock of the practice-driven indicators (Mazzei and Ravazzani, 2008, 2012; Ravazzani, 2016), the companies reveal a diversity and inclusion management approach paying equal attention to social and business-oriented aspects. Company A places strong focus on meeting social expectations, according to an "Integrating Diversity" approach, but most recently also on increasing company competitiveness, closer to a "Leveraging Variety" approach. On the one hand, the action geared towards safeguarding equal opportunities for women is coupled with practices focused on a greater array of differences that increase equity of treatment as well as employee motivation and wellbeing, addressing the heightened sensitivity in society towards these issues. On the other hand, diversity and inclusion are placed at the core of the company strategy with the competitive goal of better understanding the customers' diverse makeup and needs, where "systemic diversity" (Christensen et al., 2008) helps to sense and acknowledge differences in the organizational surroundings. Company B is more clearly inspired by a "Leveraging Variety" approach where diversity, especially in its dimensions of competencies and skills, is pursued for and evaluated against competitive and innovation outcomes. Still the wide array of diversity dimensions considered by Company B and its focus on ensuring employees' safety and well-being highlights its holistic vision of diversity. This is in line with what Frémeaux (2020) suggests: companies should not see the rationales for equality, diversity, and inclusion as separate but rather embrace and mould economic, social, and moral aspects.

Second, the companies' diversity and inclusion strategy and practices reveal sensitivity and responsiveness to the macro socio-cultural system in which they operate (Jonsen et al., 2011). Gender and parenthood appear as the most relevant dimensions addressed in both cases with practices focused on flexible working, work-life balance, extension of the recruitment pool. This finding could be linked to the specific Italian societal context, where women's rights and gender equality issues are at the centre of the current public debate agenda in terms of gender pay gap (World Economic Forum, 2019), low presence of women in the C-suite (Osservatorio 4. Manager, 2020), lack of women in scientific studies (Save the Children, 2021), violence against women (Istat, n.a.), and sexual harassment (Save the Children, 2020).

Considering these two common features, this study confirms a nuanced and holistic view of diversity and inclusion management in Italy, as already emerged in the previous study of Ravazzani (2016). Society (societal demands), organization (corporate culture) and individual (personal awareness and growth) levels are to be seen as equally relevant and pursued simultaneously in a more balanced approach to diversity and inclusion (De Anca and Vásquez, 2007). Results show that both Company $\mathrm{A}$, which has foreign origins, and Company $\mathrm{B}$, which is Italian, do not of practice developments in Italy 
sinergie Vol. 39, Issue 3, 202

follow a predetermined path but rather build their own approach based on macro socio-cultural influences as well as organization-related factors and needs. Considering organizational conditions, the international nature of both companies makes them exposed to the globalisation of diversity management concepts and prone to see diversity as an asset to innovate and respond to heterogeneous customer needs (Ravazzani, 2016). Other organization-specific elements, however, explain differences in their approach: for example, linking diversity to their corporate strategy, Company A places more emphasis on women and (technological and nontechnological) gender divides, while Company B focuses on safety and varied competencies for interdisciplinary collaboration.

The analysis of the two companies also gives insights into the organizational challenge created by the increase of heterogeneity in workplaces, regardless of the national context in which an organization may operate: the risk of losing shared organizational identity and purpose leading the organizing process. Organizations look for integration and consistency while, simultaneously, hope to retain sufficient diversity to operate and better respond to complex markets (Christensen et al., 2008). The two case studies show three practices capable of containing the risk of losing shared organizational identity and purpose: a) developing a culture of diversity and an inclusive and respectful language; b) integrating diversity into core processes; c) implementing diversity as part of the company purpose.

a) Both companies are highly involved in the development of a culture of diversity: Company A puts diversity and inclusion at the core of the corporate mission and tries to build a shared diversity agenda with a bottom-up process (the Manifesto) involving the entire organization; similarly, Company B aims to create an inclusive corporate culture. Literature underlines that to take advantage from internal diversity, organizations should develop an organizational setting where diversity is present at all organizational levels and conceived as a basic value in the corporate culture to be embraced and encouraged (Cox, 1991; Holzinger and Dhalla, 2007). Interestingly, both companies strive to build an inclusive and respectful language. This supports the idea of language as a means for leading cultural change in organizations through sensemaking (Weick, 1995) and as a starting point for creating a common background for mutual understanding (Pless and Maak, 2004). People inside an organization should foster the "competencies of inclusions": respect and empathy, recognition of differences together with equality, appreciation for different voices, frank communication, participation, integrity, consultative leadership (Pless and Maak, 2004). While a language respectful of all differences is key to sensemaking, scholars advise to preserve strategic ambiguity to create a unified diversity: the ability for differences to co-exist within the unity of the organization, essential to the process of organizing (Christensen and Cornelissen, 2011; Eisenberg, 1984). To this end, polyphony may even be a conscious organizational strategy designed to foster identification and reduce tension by allowing different audiences to apply multiple interpretations to what is seen as one corporate message (Christensen et al., 2010). 
b) A second practice is the effort to integrate diversity into the core processes of the two organizations for a better competition. Company A wants to increase diversity for a better understanding of customers' needs; Company B values diversity to sustain innovation processes and interdisciplinary projects. This strategic take on diversity allows to manage the so called "controlled chaos" (Wang and Rafiq, 2009, p. 17 ), i.e. integrating diversity into the implementation of organizational goals to protect the effectiveness of coordination, cohesiveness, and collaboration, as well into the company's mainstream work and core functions (Thomas and Ely, 1996).

c) Finally, the two case studies underline how the companies are implementing diversity as part of the company purpose. In both companies, diversity commitment is of quite recent introduction but is part of the corporate mission, sponsored by the top management and linked to social causes. The analysis shows that in these two companies, diversity is becoming part of the organizational purpose (Danesh, 2020; George et al., 2021). Having a socially desirable purpose facilitates the coexistence of multiple perspectives, values, and cultures (Di Fabio, 2017). Developing at the organizational level a purpose that is oriented to the societal pressures and that can be recognized as desirable from all organizational members allows organizations to create a zone of acceptance in the long run (De Anca and Vásquez, 2007).

To sum up, this study contributes to understanding practice developments related to diversity and inclusion in Italy and does so from a longitudinal perspective, building on previous research efforts (i.e., Mazzei and Ravazzani, 2012; Ravazzani, 2016). First, it confirms the relevance of a nuanced approach embracing the variety of the whole person to increase motivation and wellbeing as well as to value individual competencies and knowledge-related differences for competition. Second, it highlights the significant effort of both companies towards the gender issue, showing that country-specific factors contribute to steer the diversity and inclusion management practices of organizations in Italy. In this sense, this study underlines the relevance of adopting a national perspective (Klarsfeld, 2009) since specific factors that shape the understanding and practice of diversity and inclusion management in organizations, such as antidiscrimination legislation, history of immigration, productive system, social and cultural features, all differ among countries. Also, such a countrysensitive perspective must be complemented by attention to organizational factors and needs that may similarly shape the organizational approach (Olsen and Martins, 2012; Shore et al., 2009). In line with these contextaware considerations, this study also shows the need to balance the quest for employee heterogeneity with the quest for collective meaning creation and shared purpose by developing a truly inclusive culture, embedding diversity into core organizational processes, and adopting an organizational purpose that is oriented towards societal expectations and evolution.

\section{Practical implications}

Considering the findings of this study, organizations are advised to take into consideration their context specificities when shaping their diversity
Silvia Ravazzani

Alessandra Mazze

Chiara Fisichella

Alfonsa Butera

Diversity and inclusion

management: an analys

of practice developments in Italy 
sinergie Vol. 39, Issue 3, 202

and inclusion approach and initiatives. This can help organizations to sustain the relevance of their efforts at a societal level and sustain the engagement of their employees in diversity and inclusion management initiatives. Moreover, organizations are to face the crucial challenge of balancing the quest for heterogeneity with the quest for collective meaning creation and shared purpose. This challenge can be overcome by adopting organizational practices such as the creation of an inclusive organizational culture, where variety is one of the key organizational values; the incorporation of diversity into organizational processes; the creation of an organizational purpose oriented to societal pressures which function as a centre of gravity for the organizing process around which a certain degree of diversity can be tolerated. The acceptance of the organizational purpose represents the minimum degree of similarity required to engage people in a meaning creation process with an acceptable rate of success.

\section{Future research}

From a methodological point of view, the case study approach allowed to delve into the specificities of selected organizational realities to see how diversity is understood and acted upon in practice. Similarly, other studies carried out in different national contexts with a case study methodology have offered such detailed examinations, revealing for example the ambiguities, contradictions, and paradoxes created in the efforts to implement diversity management (e.g., Risberg, 2020).

Additional studies are needed to enlarge the number of companies and organization-specific conditions explored in Italy, including for example local companies as well as multinational companies of Italian and nonItalian ownership. Moreover, findings are to be integrated with a deeper analysis of explanatory contextual factors, including the organizational factors already explored in Ravazzani (2016), to understand "whether and how an organization's approach might change over time and/or in accordance with environmental demands" (Olsen and Martins, 2012) following the "rhythms of contingencies" (Risberg, 2020). In this sense, this study lays the foundations for new quantitative research to continue in this longitudinal perspective. Finally, future comparative research could analyse in more detail if and how formal policies and guidelines play out the way they are stated, and are given shape in the interpretation of the managers responsible for these policies; also, particular attention should be given to the employees' perspective to understand how they perceive both corporate policies and managers' efforts.

\section{References}

CHRISTENSEN L.T., MORSING M., CHENEY G. (2008), Corporate Communications. Convention, Complexity, and Critique, Sage, London.

CHRISTENSEN L.T., MORSING M., THYSSEN O. (2010), "The polyphony of corporate social responsibility. Deconstructing accountability and transparency in the context of identity and hypocrisy", in Cheney G., May S., Munshi D., (edited by), Handbook of communication ethics, Routledge, New York, NY. 
CHRISTENSEN L.T., CORNELISSEN J. (2011), "Bridging corporate and organizational communication: review, development and a look to the future", Management Communication Quarterly, vol. 25, n. 3, pp. 383-414.

COX T.H. (1991), “The multicultural organization”, Academy of Management Executive, vol. 5, n. 2, pp. 34-47.

COX T.H., BLAKE S. (1991), "Managing cultural diversity: Implications for organizational competitiveness", Academy of Management Executive, vol. 5 , n. 3, pp. 45-56.

DANESH G.S. (2020), "Who cares about organizational purpose and corporate social responsibility, and how can organizations adapt? A hypermodern perspective", Business Horizons, vol. 63, n. 4, pp. 585-594.

DAYMON C., HOLLOWAY I. (2011), Qualitative research methods in public relations and marketing communications ( $2^{\text {nd }}$ ed.), Routledge, London.

DE ANCA C., VÁSQUEZ A. (2007), Managing diversity in the global organization, Palgrave Macmillan, London.

DI FABIO A. (2017), "Positive healthy organizations: promoting well-being, meaningfulness, and sustainability in organizations", Frontiers in Psychology, vol. 8, n. 1938, pp. 1-6.

DUTTON J.E., DUKERICH J.M., HARQUAIL C.V. (1994), “Organizational images and member identification", Administrative Science Quarterly, vol. 39, n. 2, pp. 239-263.

EISENBERG E.M. (1984), "Ambiguity as strategy in organizational communication", Communication Monographs, vol. 51, n. 3, pp. 227-242.

ELLINGRUD K., KRISHNAN M., KRIVKOVICH A., KUKLA K., MENDY A., ROBINSON N., SANCIER-SULTAN S., YEE L. (2020), Diverse employees are struggling the most during COVID-19 - here's how companies can respond, Mckinsey, available at https://www.mckinsey.com/featuredinsights/diversity-and-inclusion/diverse-employees-are-struggling-themost-during-covid-19-heres-how-companies-can-respond

EUROPEAN UNION AGENCY FOR FUNDAMENTAL RIGHTS (2020), A long way to go for LGBTI equality, available at https://fra.europa.eu/en/ publication/2020/eu-lgbti-survey-results

FLYVBJERG B. (2006), "Five misunderstandings about case-study research", Qualitative Inquiry, vol. 12, n. 2, pp. 219-245.

FRÉMEAUX S. (2020), "A common good perspective on diversity", Business Ethics Quarterly, vol. 30, n. 2, pp. 200-228.

GEORGE G., HAAS M.R., MCGAHAN A.M., SCHILLEBEECKX S.J.D., TRACEY P. (2021), "Purpose in the for-profit firm: A review and framework for management research", Journal of Management, https://journals.sagepub. com/doi/10.1177/01492063211006450

GIOIA D.A., CORLEY K.G., HAMILTON A.L. (2013), "Seeking Qualitative Rigor in Inductive Research: Notes on the Gioia Methodology", Organizational Research Methods, vol. 16, n. 1, pp. 15-31.

HOLZINGER I., DHALLA R. (2007), "Multiple identities in organizations: the effects of diversity on organizational identity", The International Journal of Diversity in Organisations, Communities and Nations, vol. 7, n. 5, pp. 43-50.

ISTAT (n.a.), Violenza sulle donne, available at http://dati-violenzadonne.istat.it/

JONSEN K., MAZNEVSKI M.L., SCHNEIDER S.C. (2011), "Diversity and its not so diverse literature: an international perspective", International Journal of Cross Cultural Management, vol. 11, n. 1, pp. 35-62.
Silvia Ravazzani

Alessandra Mazze

Chiara Fisichella

Alfonsa Butera

Diversity and inclusion

management: an analysi

of practice developments

in Italy 
KANDOLA R., FULLERTON J. (2004), Managing the mosaic: Diversity in action, IPD House, London.

KLARSFELD A. (2009), "The diffusion of diversity management: The case of France", Scandinavia Journal of Management, vol. 25, n. 4, pp. 363-373.

KONRAD A. (2003), "Defining the domain of workplace diversity scholarship", Group and Organization Management, vol. 28, n. 1, pp. 4-17.

LIFF S. (1997), "Two routes to managing diversity: individual differences or social group characteristics”, Employee Relations, vol. 19, n. 1, pp. 11-26.

MAZZEI A., RAVAZZANI S. (2008), "Leveraging differences in a global competitive context: a qualitative analysis", Proceedings of the $7^{\text {th }}$ International Marketing Trends Conference, Venezia, Italy, 17-19 January.

MAZZEI A., RAVAZZANI S. (2012), "Leveraging variety for creativity, dialogue and competition", Journal of Communication Management, vol. 16, n. 1, pp. 59-76.

MILLIKEN F.J., MARTINS L.L. (1996), "Searching for common threads: understanding the multiple effects of diversity in organizational groups", Academy of Management Review, vol. 21, n. 2, pp. 402-433.

MURGIA A., POGGIO B. (2014), "Moving societies and immobile organizational practices. The winding road of diversity management in Italy", in Klarsfeld A., (edited by), International Handbook on Diversity Management at Work: Country and Thematic Perspectives on Diversity and Equal Treatment $\left(2^{\text {nd }}\right.$ ed.), Edward Elgar, Cheltenham.

OLSEN J.E., MARTINS L.L. (2012), "Understanding organizational diversity management programs: a theoretical framework and directions for future research", Journal of Organizational Behavior, vol. 33, n. 8, pp. 1168-1187.

OSSERVATORIO 4.MANAGER (2020), Nuovi orizzonti manageriali. Donne al timone per la ripresa del paese, available at https://www.4manager.org/wpcontent/uploads/2020/12/4manager-nuovi_orizzonti-schermo-1.pdf

PATTON M.Q. (2002), Qualitative research and evaluation methods (3 ${ }^{\text {rd }}$ ed.), Sage Publications, Thousand Oaks, CA.

PLESS N., MAAK T. (2004), "Building an inclusive diversity culture: principles, processes and practice", Journal of Business Ethics, vol. 54, n. 2, pp. 129-147.

RAVAZZANI S. (2016), "Understanding approaches for managing diversity in the workplace: an empirical investigation in Italy", Equality, Diversity and Inclusion: an International Journal, vol. 35, n. 2, pp. 154-168.

RISBERG A. (2020), "Constantly trying organizations: Ambiguities, contradictions, and paradoxes in diversity work", paper presented at NEON 2020 Conference, Norway, November 18-19.

SAVE THE CHILDREN (2020), Violenza contro le donne, available at https://www. savethechildren.it/press/violenza-contro-le-donne-il-70-delle-ragazzedichiara-di-aver-subito-molestie-e-apprezzamenti

SAVE THE CHILDREN (2021), Giornata internazionale delle donne e delle ragazze nella scienza: in Italia bambine vittime delle disuguaglianze di genere, available at https://www.savethechildren.it/press/giornata-internazionaledelle-donne-e-delle-ragazze-nella-scienza-italia-bambine-vittime-delle

SCOTT S.G., LANE V.R. (2000), "A stakeholder approach to organizational identity", Academy of Management Review, vol. 25, n. 1, pp. 43-62.

SHEN J., CHANDA A., D’NETTO B., MONGA M. (2009), "Managing diversity through human resource management: an international perspective and conceptual framework", The International Journal of Human Resource Management, vol. 20, n. 2, pp. 235-251. 
SHORE L.M., CHUNG-HERRERA B.G., DEAN M.A., EHRHART K., JUNG D.I., RANDEL A.E., SINGH G. (2009), "Diversity in organizations: where are we now and where are we going?", Human Resource Management Review, vol. 19, n. 2, pp. 117-133.

SÜB S., KLEINER M. (2008), "Dissemination of diversity management in Germany: a new institutionalist approach", European Management Journal, vol. 26, n. 1, pp. 35-47.

SVETELIK A. (2006), "Diversity and Diversity Management: A Comparative Advantage?", in H.H. Larsen and W. Mayrhofer, (edited by), Managing Human Resources in Europe. A Thematic Approach (pp. 217-235), Routledge, New York.

THOMAS D.A., ELY R.J. (1996), "Making differences matter: a new paradigm for managing diversity", Harvard Business Review, vol. 74, n. 5, pp. 79-90.

WANG C.L., RAFIQ M. (2009), "Organizational diversity and shared vision: resolving the paradox of exploratory and exploitative learning", European Journal of Innovation Management, vol. 12, n. 1, pp. 86-101.

WEICK K.E. (1995), Sensemaking in organizations, Sage, Thousand Oaks, CA.

WORLD ECONOMIC FORUM (2019), Global Gender Gap Report, available at http://www3.weforum.org/docs/WEF_GGGR_2020.pdf

YIN R.K. (2003), Case study research. Design and methods ( $3^{\text {rd }}$ ed.), Sage Publications, Thousand Oaks, CA.

\section{Academic or professional position and contacts}

\section{Silvia Ravazzani}

Associate Professor of Management

Università IULM, Milan - Italy

e-mail: silvia.ravazzani@iulm.it

\section{Alessandra Mazzei}

Associate Professor of Management

Università IULM, Milan - Italy

e-mail: alessandra.mazzei@iulm.it

\section{Chiara Fisichella}

Adjunct Professor

Università IULM, Milan - Italy

e-mail: chiara.fisichella@iulm.it

\section{Alfonsa Butera}

Adjunct Professor

Università IULM, Milan - Italy

e-mail: alfonsa.butera@iulm.it
Silvia Ravazzani Alessandra Mazze Chiara Fisichella

Alfonsa Butera

Diversity and inclusio management: an analysis of practice developments in Italy italian journal of ergie

ISSN 0393-5108 DOI 10.7433/s116.2021.1 pp. 213-229 